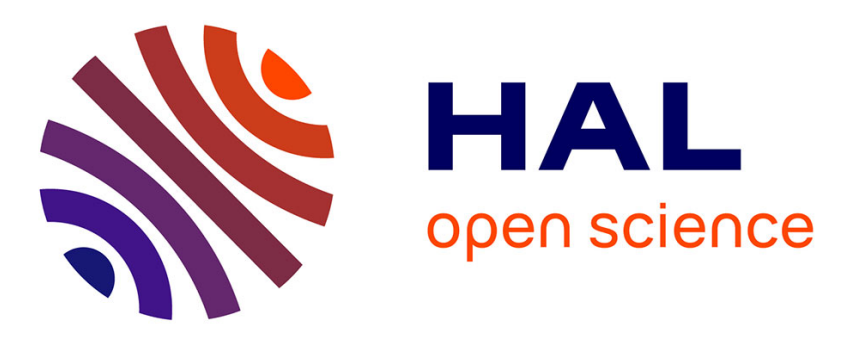

\title{
Thermodynamic study of benzene and hydrogen coadsorption on $\mathrm{Pd}(111)$
}

Gonzalo Canduela-Rodriguez, Marteen Sabbe, Jean-Francois Joly, Marie.-Françoise Reyniers, Guy B Marin

\section{- To cite this version:}

Gonzalo Canduela-Rodriguez, Marteen Sabbe, Jean-Francois Joly, Marie.-Françoise Reyniers, Guy B Marin. Thermodynamic study of benzene and hydrogen coadsorption on $\mathrm{Pd}(111)$. ChemPhysChem, 2014, 16 (43), pp.23754 - 23768. 10.1039/C4CP02991G . hal-01091115

\section{HAL Id: hal-01091115 \\ https://hal-ifp.archives-ouvertes.fr/hal-01091115}

Submitted on 5 Dec 2014

HAL is a multi-disciplinary open access archive for the deposit and dissemination of scientific research documents, whether they are published or not. The documents may come from teaching and research institutions in France or abroad, or from public or private research centers.
L'archive ouverte pluridisciplinaire HAL, est destinée au dépôt et à la diffusion de documents scientifiques de niveau recherche, publiés ou non, émanant des établissements d'enseignement et de recherche français ou étrangers, des laboratoires publics ou privés. 


\section{Thermodynamic study of benzene and hydrogen coadsorption on $\operatorname{Pd}(111)$}

Suggested authors: Gonzalo Canduela-Rodriguez ${ }^{\mathrm{a}}$, Maarten. K. Sabbe ${ }^{\mathrm{a}}$, Jean.-François Joly ${ }^{\mathrm{b}}$, Marie.-Françoise Reyniers ${ }^{\mathrm{a}^{*}}$ and Guy. B. Marin ${ }^{\mathrm{a}}$

${ }^{\mathrm{a}}$ Laboratorium voor Chemische Technologie, Universiteit Gent, Technologiepark 914, B9052 Gent, Belgium

${ }^{\mathrm{b}}$ IFP Energies nouvelles, BP 3 - 69360 Solaize - France

*Corresponding author. Email: MarieFrancoise.Reyniers@UGent.be 


\section{Supporting information}

\section{Thermodynamic calculations:}

Three different approaches have been used to evaluate surface free energies. The first one is defined as $P W 91-G$, in which the Gibbs free energy for the adsorbate system $\left(G_{a d s}\right)$ and bulk $\left(G_{\text {bulk }}\right)$ are calculated as shown in eq. (4), from the enthalpy and entropy terms, which include vibrational contributions and consider immobile species. In this equation, the enthalpy consists of the sum of electronic energy $E_{\mathrm{el}}$, the zero point vibrational energy (ZPVE), and the thermal correction to the enthalpy $U_{v i b}$ :

$$
G=(H-T \cdot S)=\left(E_{e l}+Z P V E+U^{v i b}\right)-T \cdot S_{v i b}
$$

The molar gas phase Gibbs free energy, $G_{\text {gas }}$, accounts for the same terms as the ones in eq. (4), but also considers the free energy contributions from the translational and rotational gas phase modes, $U^{\text {trans+rot }}$ and $S^{\text {trans+rot }}$, which are also calculated from statistical thermodynamics. Additionally, the molar gas phase Gibbs free energy includes the term that accounts for the gas phase pressure, in which $k_{B}$ is the Boltzmann constant, $T$ the temperature $(\mathrm{K}), p_{i}$ the pressure of the gas phase species $i$ (bar), and $p^{o}$ the standard pressure of 1 bar, as shown in eq. (5).

$$
G_{m, g a s}=\left(H_{g a s, i}-T \cdot S_{g a s}\right)=\left[\left(E_{e l}+Z P V E+U^{v i b}+U^{\text {trans }+r o t}\right)\right]-T \cdot\left(S^{v i b}+S^{\text {trans }+ \text { rot }}\right)+R \cdot T \cdot \ln \frac{p_{\text {gas }}}{p^{o}}
$$

The unit cell used in the calculation has two surfaces because a vacuum layer is included between periodic images to avoid interactions in the direction perpendicular to the slab. The Pd atoms in the upper surface are relaxed during the geometry optimization ("top surface"), on which the corresponding coverage of species $i$ is adsorbed. However, the Pd atoms that compose the lower ("bottom”) surface are constrained to the bulk geometry, and on this surface no species are adsorbed (i.e. mixed slab in Figure 1). The electronic energy obtained from the periodic DFT calculations corresponds to the whole slab, which includes these two surfaces. Therefore, the surface free energy that can be derived from this electronic energy corresponds to an average value of these two surfaces, while only the upper one is of interest. 
In order to calculate an approximate value for a completely optimized surface $\left(\Gamma_{\text {el,relaxed }}\right)$, the following was proposed by Chizallet et al. [10] and is done in this work; the average surface energy of the mixed-surface unit cell is counted two times (mixed slab), and the surface energy of a completely non-optimized unit cell (fixed slab) is subtracted, i.e. energy of the unit cell with all atoms in the bulk structure and without adsorbate (see eq. (6) and Figure 1).

$$
\Gamma_{\text {el, relaxed }}=2 \cdot\left(\frac{E_{e l, a d s}-n_{P d} \cdot E_{\text {el,bulk }}-\sum_{i} n_{i} \cdot E_{\text {el, gas }, i}}{2 \cdot A}\right)_{\text {mixed }}-\left(\frac{E_{e l, \text { unitcell }}-n_{P d} \cdot E_{\text {el,bulk }}}{2 \cdot A}\right)_{\text {fixed }}
$$

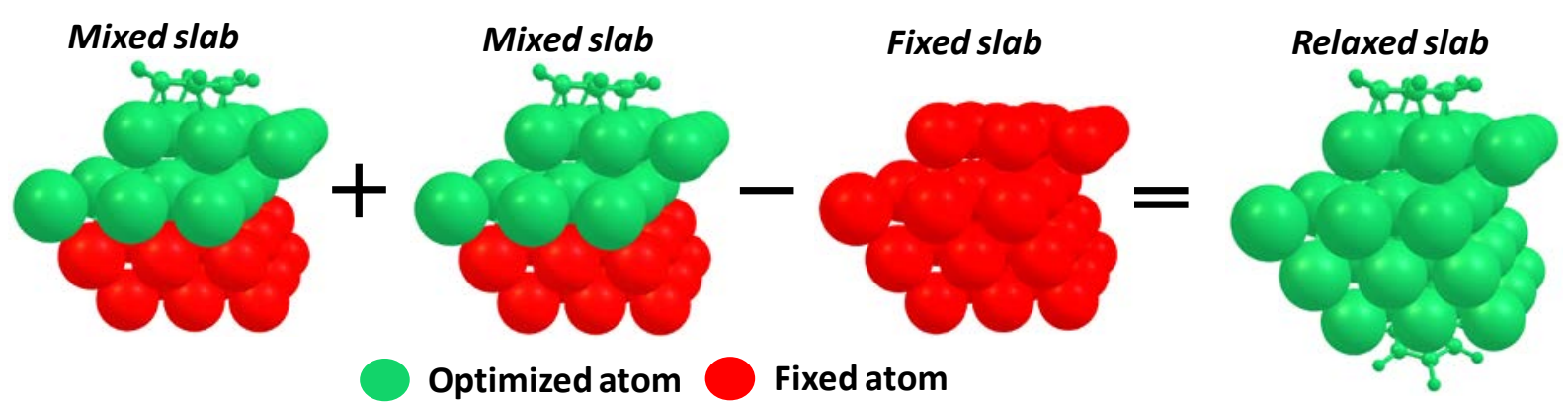

Figure 1: Scheme illustrating the calculation of the surface free energy of a fully optimized surface, obtained from the mixed and fixed slabs. To avoid the use of an average surface free energy between an optimized and non-optimized surface, the electronic energy of the regular unit cell (with one optimized and another non-optimized surfaces) is accounted two times, and the electronic energy of a non-optimized unit cell is subtracted.

Substituting eq. (4), eq. (5) and eq. (6) into eq. (3), the surface free energy in case1: PW91-G is obtained as shown in eq. (7). The adsorbate, bulk and gas phase contributions are multiplied by two because of the definition of the electronic energy term in eq. (6). Furthermore, the $\Gamma_{(T, p)}$ can be also written in terms of the contribution from the electronic energy $\left(\Gamma_{\text {el,relaxed }}\right)$, enthalpy (ZPVE $+U_{\text {vib }}$ terms) $\left(\Gamma_{H}\right)$ and entropy $\left(\Gamma_{S}\right)$, together with the gas pressure term, as shown in eq. (8). Mind that the electronic energy is not included in the enthalpy term, and that the temperature is included in the entropy term. These terms are useful for comparing the cases that include or not vibrational contributions by defining the free energy contribution from the thermochemistry, sum of enthalpy and entropy terms or $\Gamma_{\text {thermochem }}=\Gamma_{H}+\Gamma_{S}$. Each enthalpy and entropy term is, in turn, calculated as the difference between the system and bulk + gas phase terms. 


$$
\begin{aligned}
& \Gamma_{T, p}=\Gamma_{\text {el, relaxed }}+2 \cdot \frac{\left(\left(Z P V E+U^{v i b}\right)-T \cdot S^{v i b}\right)_{a d s}}{2 \cdot A}-2 \cdot \frac{\frac{n_{P d}}{2} \cdot\left(\left(Z P V E+U^{v i b}\right)-T \cdot S^{v i b}\right)_{b u l k}}{2 \cdot A}- \\
& -2 \cdot n_{i}\left(\frac{\sum_{i}\left(\left(Z P V E+U^{v i b}\right)-T \cdot\left(S^{v i b}+S^{\text {trans }+ \text { rot })}+R \cdot T \cdot \ln \left(\frac{p_{i}}{p^{o}}\right)\right)_{\text {gas }, i}\right.}{2 \cdot A}\right) \\
& \Gamma_{T, p}=\Gamma_{\text {el, relax }}+\left(\Gamma_{H, \text { ads }}-\Gamma_{H, \text { bulk }}-\Gamma_{H, \text { gas }}\right)+\left(\Gamma_{S, \text { ads }}-\Gamma_{S, \text { bulk }}-\Gamma_{S, \text { gas }}\right)-2 \cdot n_{i}\left(\frac{R \cdot T \cdot \ln \left(\frac{p_{i}}{p^{o}}\right)}{2 A}\right)= \\
& =\Gamma_{\text {el, relax }}+\Gamma_{H}+\Gamma_{S}-2 \cdot n_{i}\left(\frac{R \cdot T \cdot \ln \left(\frac{p_{i}}{p^{o}}\right)}{2 A}\right)
\end{aligned}
$$

In literature, a common approach is to approximate the Gibbs free energy to the electronic energy from DFT, thus neglecting vibrational contributions in the enthalpy and entropy, because the calculation of vibrational frequencies is not straightforward for many systems and time consuming. This case is defined in this work as $P W 91-E_{e l}$. Although this approach neglects vibrational contributions for gas phase species, it considers free energy contributions from the translational and rotational gas phase modes $\left(H^{\text {trans }+ \text { rot }}\right.$ and $\left.S^{\text {trans }+ \text { rot }}\right)$. The surface free energy as a function of the conditions is calculated in $P W 91-E_{e l}$ following eq. (10), which in turn is also writen, as for $P W 91-G$ approach in eq. (8), as the sum of the different terms in eq. (9).

$$
\begin{aligned}
& \Gamma_{(T, p)}=\Gamma_{\text {el, relax }}-2 \cdot\left(\frac{\sum_{i}\left(\left[H_{\text {trans }+ \text { rot }}(T)\right]_{\text {gas }, i}-\left(T \cdot S_{\text {trans }+ \text { rot }}(T)\right)_{\text {gas }, i}+R \cdot T \cdot \ln \left(\frac{p_{\text {gas }, i}}{p^{o}}\right)\right)}{2 A}\right)= \\
& =\Gamma_{\text {el, relax }}+\Gamma_{H}+\Gamma_{S}-2 \cdot n_{i}\left(\frac{R \cdot T \cdot \ln \left(\frac{p_{i}}{p^{o}}\right)}{2 A}\right)
\end{aligned}
$$




\section{Results}

Table S1: Adsorption energies in $\mathrm{kJ} \mathrm{mol}^{-1}$ of hydrogen adsorbed at different coverages and sites up to saturation coverage. The values obtained with the vdW-DF functional for the hollow fcc site are shown between brackets.

\begin{tabular}{lcccc}
\hline \multirow{2}{*}{ Site } & \multicolumn{4}{c}{$\Delta E_{a d s}\left(\mathrm{~kJ} \mathrm{~mol}_{\mathrm{H}}{ }^{-1}\right)$} \\
& $0.25 \mathrm{ML}$ & $0.5 \mathrm{ML}$ & $0.75 \mathrm{ML}$ & $1 \mathrm{ML}$ \\
\hline fcc & $-54.2(-43.4)$ & $-51.5(-40.6)$ & $-49.5(-38.3)$ & $-47.9(-36.6)$ \\
hcp & -49.3 & -46.6 & -44.5 & -42.9 \\
bridge & -39.2 & -35.9 & -32.6 & -29.1 \\
top & -1.6 & 1.1 & 3.5 & 7.0 \\
octasub & -17.0 & -15.6 & -15.2 & -14.5 \\
tetrasub31 & -17.6 & -17.6 & -18.4 & -19.6 \\
tetrasub13 & -13.5 & -13.6 & -13.8 & -14.4 \\
\hline
\end{tabular}


Table S2: Adsorption energy $\left(\mathrm{kJ} \mathrm{mol}^{-1}\right)$ per mol of hydrogen for the adsorption of $0.25 \leq$ $\Theta_{\mathrm{H}} \leq 1$ hydrogen coverage on a covered slab with $\Theta_{\mathrm{H} \text {,initial }}=1$, for different combinations. The values obtained with the vdW-DF functional for the combination of $\Theta_{H}=1$ hydrogen fcc and addition of $0.25 \leq \Theta_{\mathrm{H}} \leq 1$ tetrasub13 hydrogen is shown between brackets.

\begin{tabular}{|c|c|c|c|c|c|}
\hline$\Theta_{\mathrm{H}, \text { initial }}=1$ & $0.25 \leq \Theta_{\mathrm{H}} \leq 1$ & \multicolumn{4}{|c|}{$\Delta E_{a d s}\left(\mathrm{~kJ} \mathrm{~mol}_{\mathrm{H}}^{-1}\right)$} \\
\hline \multirow{4}{*}{ fcc } & tetrasub31 & -38.6 & -32.5 & -27.6 & -24.2 \\
\hline & octasub & -38.9 & -32.7 & -28.0 & -23.3 \\
\hline & tetrasub13 & $-39.8(-28.3)$ & $-34.3(-22.6)$ & $-30.1(-18.4)$ & $-26.8(-15.1)$ \\
\hline & hср & -33.1 & -20.0 & -0.3 & 19.1 \\
\hline \multirow{4}{*}{ hср } & octasub & -36.3 & -31.7 & -28.0 & -24.2 \\
\hline & tetrasub31 & -30.5 & -23.2 & -18.0 & -14.9 \\
\hline & tetrasub13 & -36.1 & -31.5 & -27.9 & -25.2 \\
\hline & fcc & -30.3 & -20.0 & 0.0 & 19.1 \\
\hline \multirow{3}{*}{ top } & octasub & 5.0 & 3.2 & 1.6 & 0.4 \\
\hline & tetrasub31 & 7.3 & 6.4 & 4.7 & 2.5 \\
\hline & tetrasub13 & 5.9 & 4.5 & 2.7 & 1.1 \\
\hline \multirow{5}{*}{ octasub } & fCC & -18.3 & -20.8 & -22.8 & -23.3 \\
\hline & hср & -18.4 & -21.6 & -23.7 & -24.2 \\
\hline & top & -8.4 & -4.4 & -1.0 & 0.4 \\
\hline & tetrasub31 & -5.0 & -2.1 & 0.9 & 1.3 \\
\hline & tetrasub13 & -6.7 & -3.2 & -1.8 & -0.6 \\
\hline \multirow{5}{*}{ tetrasub31 } & fcc & -23.2 & -25.3 & -25.7 & -24.2 \\
\hline & hср & -18.9 & -18.5 & -17.1 & -14.9 \\
\hline & top & -12.8 & -7.6 & -2.4 & 2.7 \\
\hline & octasub & -12.7 & -7.3 & -1.7 & 1.3 \\
\hline & tetrasub13 & -14.5 & -10.4 & -6.8 & -2.5 \\
\hline \multirow{3}{*}{ tetrasub13 } & fcc & -20.1 & -23.6 & -25.8 & -26.8 \\
\hline & hср & -19.6 & -22.6 & -24.4 & -25.2 \\
\hline & top & -10.1 & -5.9 & -2.2 & 1.1 \\
\hline
\end{tabular}




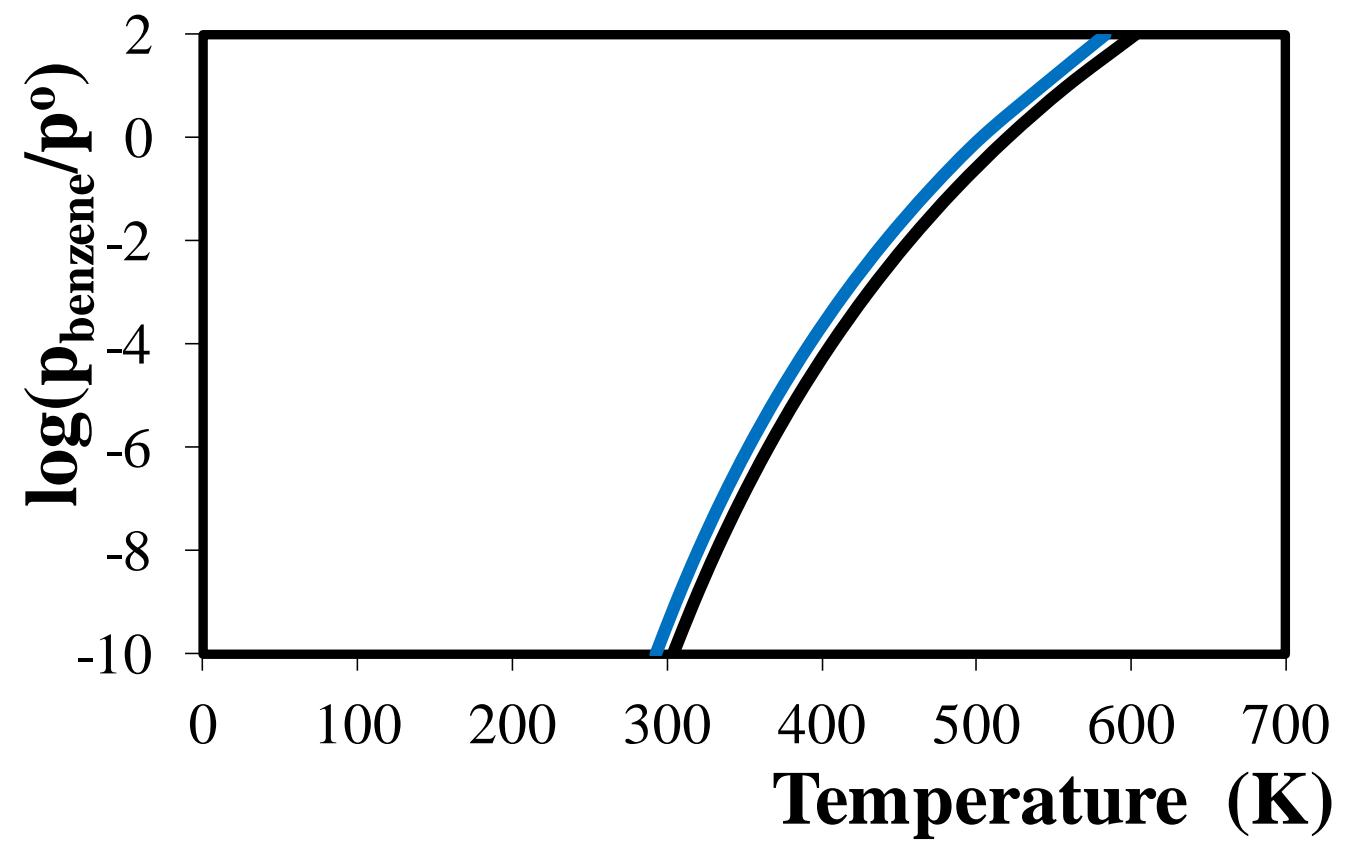

Figure 2: Thermodynamic phase diagram of benzene adsorption at the bridge(30) site on $\operatorname{Pd}(111)$ as a function of temperature $(\mathrm{K})$ and benzene pressure (bar) for standard pressure of $p^{o}=1$ bar. The electronic energies have been obtained with the PW91 functional, and free energy vibrational contributions are not included. 
Table S 3: Benzene adsorption energies in $\mathrm{kJ} \mathrm{mol}^{-1}$ on a pre-covered surface with hydrogen at surface and/or subsurface sites, and benzene adsorbing on bridge(30) or hollow-hcp(0) sites.

\begin{tabular}{|c|c|c|c|c|c|}
\hline \multicolumn{6}{|c|}{$E_{\text {ads,benzene }}(\mathrm{kJ} / \mathrm{mol})$} \\
\hline \multicolumn{3}{|c|}{ Benzene + Surface hydrogen } & \multicolumn{3}{|c|}{ Benzene + Subsurface hydrogen } \\
\hline Hydrogen coverage & Bridge(30) & Hollow-hcp $(0)$ & Hydrogen coverage & Bridge(30) & Hollow-hcp $(0)$ \\
\hline 0 & -114.9 & -100.0 & - & -114.9 & -100.0 \\
\hline 0.11 fcc & -106.0 & -89.9 & 0.11 octasub & -105.7 & -91.8 \\
\hline $0.11 \mathrm{fcc}+0.11 \mathrm{hcp}$ & -91.9 & -78.8 & 0.22 tetrasub & -100.1 & -83.7 \\
\hline $0.22 \mathrm{fcc}+0.11 \mathrm{hcp}$ & -77.0 & -70.8 & 0.22 octasub +0.11 tetrasub31 & -88.9 & -76.6 \\
\hline $0.33 \mathrm{fcc}+0.11 \mathrm{hcp}$ & -62.8 & -64.4 & 0.44 tetrasub31 & -87.1 & -71.1 \\
\hline $0.56 \mathrm{fcc}$ & -42.5 & -58.1 & 0.56 tetrasub31 & -71.0 & -59.3 \\
\hline $0.67 \mathrm{fcc}$ & -11.5 & -27.5 & 0.67 tetrasub31 & -70.7 & -56.9 \\
\hline $0.78 \mathrm{fcc}$ & 29.9 & -15.1 & 0.78 tetrasub31 & -62.1 & -54.4 \\
\hline $0.89 \mathrm{fcc}$ & 36.4 & -13.3 & 0.89 tetrasub31 & -62.0 & -51.0 \\
\hline $0.89 \mathrm{fcc}+0.11$ tetrasub31 & 35.0 & -12.5 & 1 tetrasub31 & -61.2 & -60.8 \\
\hline
\end{tabular}

Benzene + Surface $\left(\theta_{\text {surface }}=0.89\right)+$ Subsurface $\left(0.22 \leq \theta_{\text {subsurface }} \leq 1\right)$

\begin{tabular}{lcc} 
Hydrogen coverage $\left(\theta_{\text {surface }}+\theta_{\text {subsurface }}\right)$ & Bridge $(30)$ & Hollow - hcp $(0)$ \\
\hline 0.89 fcc +0.22 tetrasub13 & 33.7 & -14.0 \\
0.89 fcc +0.33 tetrasub13 & 34.5 & -15.7 \\
0.89 fcc +0.44 tetrasub13 & 27.6 & -13.4 \\
0.89 fcc +0.56 tetrasub13 & 30.5 & -13.3 \\
0.89 fcc +0.67 tetrasub13 & 32.8 & -11.3 \\
0.89 fcc +0.78 tetrasub13 & 22.7 & -10.3 \\
0.89 fcc +0.89 tetrasub13 & 24.6 & -10.0 \\
0.89 fcc +1 tetrasub13 & 23.8 & -11.5 \\
\hline
\end{tabular}


Table S 4: Geometrical parameters of benzene hollow-hcp(0) and hydrogen coadsorbed on $\operatorname{Pd}(111)$ for hydrogen coverages between 0 (clean slab) and $\theta_{H}=1.89$. Average $C-C$ bond length (pm), angle of $\mathrm{C}-\mathrm{H}$ bond relative to the $\mathrm{C}$ atom at the opposite side of the ring $\left(^{\circ}\right)$, distance between the benzene centre of mass and the Pd top layer (pm), between the two first Pd layers (pm), and finally average bond distance (pm) between all hydrogen atoms, considering that fcc sites form three bonds with the Pd atoms

\begin{tabular}{cccccc}
\hline$\theta_{\mathrm{H}}$ & $\begin{array}{c}\mathrm{C}-\mathrm{C} \\
(\mathrm{pm})\end{array}$ & $\begin{array}{c}\mathrm{C}-\mathrm{C}-\mathrm{H}^{*} \\
\left({ }^{\circ}\right)\end{array}$ & $\begin{array}{c}\text { B-Pd } \\
(\mathrm{pm})\end{array}$ & $\begin{array}{c}\text { Pd1-Pd2 } \\
(\mathrm{pm})\end{array}$ & $\begin{array}{c}\text { H-Pd } \\
(\mathrm{pm})\end{array}$ \\
\hline 0 & 143.5 & 164.8 & 209 & 230 & - \\
0.11 & 143.4 & 165.1 & 221 & 231 & 180.7 \\
0.22 & 143.2 & 165.5 & 220 & 232 & 180.9 \\
0.33 & 143.1 & 165.7 & 220 & 232 & 180.4 \\
0.44 & 143.0 & 165.8 & 221 & 233 & 180.2 \\
0.56 & 142.7 & 166.8 & 226 & 234 & 178.0 \\
0.67 & 142.2 & 168.8 & 239 & 235 & 179.2 \\
0.78 & 139.8 & 179.5 & 346 & 233 & 180.5 \\
0.89 & 139.7 & 179.8 & 386 & 233 & --- \\
1 & 139.7 & 179.8 & 387 & 235 & --- \\
1.11 & 139.7 & 179.8 & 398 & 238 & --- \\
1.22 & 139.7 & 179.8 & 389 & 243 & --- \\
1.33 & 139.7 & 179.8 & 385 & 247 & --- \\
1.44 & 139.7 & 179.8 & 382 & 251 & --- \\
1.56 & 139.7 & 179.8 & 379 & 255 & --- \\
1.67 & 139.7 & 179.8 & 380 & 259 & --- \\
1.78 & 139.7 & 179.8 & 383 & 263 & --- \\
1.89 & 139.7 & 179.8 & 383 & 268 & --- \\
Benzene gas phase & 140.0 & 180.0 & - & - & - \\
\hline
\end{tabular}

* Corresponding to the carbon atoms at the opposite side of the aromatic ring. 